\title{
Book Review: The Vietnamese Social Sciences at a Fork in the Road
}

\author{
Bui Dieu Quynh \\ National Centre for Sustainable Development of General Education Quality \\ Vietnam National Institute of Educational Sciences
}

101 Tran Hung Dao street, Hoan Kiem District, Hanoi 100000, Vietnam

Email: buidieuquynh2019@gmail.com

Hanoi, November 7, 2019

For individual researchers and academics, research outputs are a crucial asset that enables public gaining of recognition and acknowledgments of their expertise. For institutions, industry sectors, and countries, scientific publications serve a more critical role, being a measure and an index that indicates scientific development and competitiveness. As a country that is transitioning to modernization and industrialization, Vietnam recognizes science and education as the driving force for its socio-economic development. The government has made sizeable efforts to enhance the research capacity for research institutes and higher education establishments across the country. This involves introducing policies that prioritize research activities and elevating research funding and monitoring schemes to some certain levels.

Documenting research productivity of Vietnam is a significant study that a group of Vietnamese scholars and educators have contributed to the literature. The Vietnamese Social Sciences at a Fork in the Road freshly released in October 2019 in English by Sciendo, Walter de Gruyter, and was edited by two influential Vietnamese researchers, Quan-Hoang Vuong and Trung Tran [1]. The chapters in the monograph were contributed by sixteen reputed Vietnamese researchers, all of whom have published extensively on social sciences and humanities topics. The book is among the first of its kind that has systematically collected and presented detailed and concrete findings on Vietnam's research productivity in the field of humanities and social sciences within the past decade. This is enlightening in the sense that humanities and social sciences have mostly assumed an inferior role and a challenging task compared with natural sciences and technology as a result of inadequate research culture and financial incentives.

The book comprises eight chapters which provide a comprehensive and vivid picture of Vietnam's international publishing in the field of social sciences and humanities within the past ten years (2008-2018). The readers will have an opportunity to understand and appreciate Vietnam's growth in the field as well as the challenges that the country faces in international publication benchmarks. In particular, the authors provide an insight into the policy environment and policy changes that are conducive to the growth of humanities and social sciences disciplines. In addition to the rich statistical data that the book reports, more 
importantly, some critical, in-depth discussions over quality issues allow for essential implications to be made with regard to Vietnam's publishing policies and scientific publishing financing.

Research performance in Vietnam is often a point of criticism in media release due to the low quality and unmatched quantity in international indicators, even when compared with research outputs by neighboring ASEAN countries, such as Singapore, Thailand or Malaysia $[2,3,4]$. Cases of misconduct in postgraduate research training, especially doctoral training programs, at many research institutes and higher education institutions have been reported, showing how local researchers, academics and scholars could have been better supported with innovative thinking, sound research methodology and reporting schemes that could hold more currency and credibility. Drawing on such context, the book leads on to how Vietnam is embarking on a more positive change when publications have improved both in terms of quality and quantity. Timely national and institutional policy changes, noticeably state research initiatives in 2003, 2004 and 2017, have been shown to contribute to this. The establishment of the National Foundation for Science and Technology Development (NAFOSTED) in 2008 has particularly encouraged international research collaboration and national research projects in under-research areas such as health, medical and biological studies. This has resulted in an impressive figure of a five-times increase in the number of international publications indexed in Scopus by Vietnamese research within the period of 2008-2018, denoting both quality and quantity improvements. The book itself is the product of the SSHPA - a research grant under NAFOSTED's funding scheme.

The book is a reference for those interested in many aspects of the research activities in the field of social sciences and humanities by Vietnamese researchers. For one thing, it contains a comprehensive list of authors and publications that have contributed to international conferences and journals indexed in Scopus and Web of Science and NAFOSTED databases. It is also for the first time that the readers will learn about the strong achievements among female Vietnamese researchers and the extensive collaboration among research groups [5]. For another, the book provides an insight into higher education institutions and research institutes that top Vietnam's research productivity between 2008 and 2018. It discusses marked investments in research activities at these key training and research institutions, which can be used as role models for universities, research institutes and research offices country-wide that would like to build up their research capacity according to international standards. Chapter 4 is particularly useful for readers interested in research activities related to Economics studies - the filed that has steadily grown while always maintaining its top rank in publication productivity in Vietnam [6].

For early-career researchers, the book can be hugely inspiring with stories of successes from internationally influential authors who motivate and drive changes for Vietnam. This aligns with a saying by Professor Ly Tran that in order for an author to claim credibility, he or she 'must fulfil the following criteria: publishing in prestigious journals, in his or her discipline; 
authoring articles that are practically and theoretically influential; and actively participating in the assessment and building of research capacity in a specific scientific field or institute' [5]. All the chapters supply reliable, up-to-date information for reference to researchers and research institutes in Vietnam. The information can serve as the ground for further studies to be conducted in order to uphold institutional and individual research capacity and research output up to international standards. The book with its rich data and an in-depth analysis of both successes and limitations of Vietnamese social sciences and humanities studies informs and motivates Vietnamese researchers, especially female ones, in striving and naming themselves in international publications.

Policy changes in recent years have contributed significantly to the establishment of a research culture for Vietnamese educators, researchers, lecturers and teachers [7]. That research culture is arguably more grounded on international standards and benchmarks than ever before. Reading this book by Vuong and Tran [1] has motivated me, in the role of a female researcher, to engage in this research environment so that Vietnam can have its name enlisted in international publication standards and more importantly can translate research findings into practical, meaningful products.

Publishing internationally is a challenging task but inevitably an indispensable path that each Vietnamese researcher or scientist will have to embark on in this era of international integration and globalization. It is high time that research should not be seen as the sole duties of research institutes but instead should involve teachers and university lecturers who play a crucial role in delivering knowledge, finding soluble development path for the country, and motivating younger generations and colleagues [8]. This book is an eye-opening and enjoyable book to read in all those senses.

\section{References:}

[1] Vuong QH, Tran T. (Ed.) (2019). The Vietnamese Social Sciences at a Fork in the Road. Warsaw, Poland: De Gruyter. DOI: 10.2478/9783110686081.

[2] Nguyen TV, \& Pham LT. (2011). Scientific output and its relationship to knowledge economy: an analysis of ASEAN countries. Scientometrics, 89, 107-117.

[3] Manh HD. (2015). Scientific publications in Vietnam as seen from Scopus during 19962013. Scientometrics, 105, 83-95.

[4] Nguyen TV, Ho-Le TP, \& Le UV. (2017) International collaboration in scientific research in Vietnam: an analysis of patterns and impact. Scientometrics 110, 1035-1051.

[5] Doan XH, Nguyen PTT, La VP, \& Nguyen THK (2019). Researchers who lead the trends. In Vuong QH, Tran T (Eds.), The Vietnamese Social Sciences at a Fork in the Road (pp. 98-120). Warsaw, Poland: De Gruyter. doi: 10.2478/9783110686081-010. 
[6] Vu TH, Tran T, Hoang PH, \& Nguyen MH (2019). Economics: The trend-setting field. In Vuong QH, Tran T (Eds.), The Vietnamese Social Sciences at a Fork in the Road (pp. 80-97). Warsaw, Poland: De Gruyter. doi: 10.2478/9783110686081-009.

[7] Nguyen THK, Nguyen TTH, Ho MT, Ho MT, \& Vuong QH (2019). Chapter 7. Scientific publishing: the point of no return. In Vuong QH, Tran T (Eds.), The Vietnamese Social Sciences at a Fork in the Road (pp. 143-162). Warsaw, Poland: De Gruyter. doi: 10.2478/9783110686081-012.

[8] Vuong QH (2019). Breaking barriers in publishing demands a proactive attitude. Nature Human Behaviour, 3(10), 1034. doi: 10.1038/s41562-019-0667-6. 